\section{Scleral thickness in
highly myopic eyes \\ Scleral thickness in
highly myopic eyes measured by enhanced depth imaging optical coherence tomography th}

M Hayashi, Y Ito, A Takahashi, K Kawano and H Terasaki
Department of

Ophthalmology, Nagoya

University Graduate School of Medicine, Showa-ku,

Nagoya, Japan

Correspondence:

Y Ito, Department of Ophthalmology, Nagoya University Graduate School of Medicine, 65 Tsurumacho, Showa-ku, Nagoya 466-8550, Japan

Tel: + 81527442275 ;

Fax: + 81527442278

E-mail: yasu@med.

nagoya-u.ac.jp

Received: 1 October 2012 Accepted in revised form: 30 November 2012

Published online: 11 January 2013

This work was presented at the 50th annual meeting of Japanese Retina and Vitreous Society at Tokyo Japan on 3 December 2011

\begin{abstract}
Purpose The purpose of this study was to determine the subfoveal scleral thickness in highly myopic eyes by enhanced depth imaging spectral-domain optical coherence tomography (EDI-OCT) and to identify the ocular parameters significantly associated with the scleral thickness.

Methods The subfoveal scleral thickness of myopic eyes ( $\geq-8$ diopters (D) or axial length $\geq 26.5 \mathrm{~mm}$ ) was examined by EDIOCT. The correlations between the thickness and the best-corrected visual acuity (BCVA), refractive error, axial length (AL), the subfoveal retinal thickness, choroidal thickness, and posterior staphyloma height $2 \mathrm{~mm}$ from the fovea were investigated. Results A total of 75 eyes of 54 patients (21 men, 33 women; mean age, $62.3 \pm 11.3$ years; mean $\mathrm{AL}, 30.2 \pm 1.68 \mathrm{~mm}$ ) were studied. Eighteen eyes had no pathological retinochoroidal lesions, and 57 eyes had retinochoroidal lesion, that is, myopic schisis, choroidal neovascularization, and other retinochoroidal pathologies. The mean subfoveal scleral thickness was $284.0 \pm 70.4 \mu \mathrm{m}$, and the thickness was significantly correlated negatively with the absolute value of the nasal and overall average posterior staphyloma height $(P<0.05$ and $P<0.01$, respectively). The subfoveal scleral thickness was also significantly correlated negatively with the relative value of the superior, nasal, and overall average posterior staphyloma height $(P<0.05$, $P<0.01$, and $P<0.001$, respectively). Stepwise analyses showed that the factor most significantly associated with the scleral
\end{abstract}

thickness was the average relative posterior staphyloma height $(\mathrm{F}=\mathbf{1 6 . 0}, \mathbf{P}<\mathbf{0 . 0 0 1})$. The scleral thickness was not significantly different between eyes with and without myopic retinochoroidal pathologies $(P>0.05)$. Conclusion Posterior staphyloma formation was a key factor associated with a posterior scleral thinning in highly myopic eyes.

Eye (2013) 27, 410-417; doi:10.1038/eye.2012.289; published online 11 January 2013

Keywords: scleral thickness; high myopia; optical coherence tomography (OCT); posterior staphyloma; myopic complication

Introduction

Myopia is prevalent worldwide, ${ }^{1-7}$ especially among Asians. ${ }^{8,9}$ This is important because eyes with high myopia develop pathological myopia, which is a major cause of secondary blindness. ${ }^{10-13}$ The visual impairments are caused by pathological changes of the retina and choroid that frequently develop in eyes with high myopia. In addition to the retinochoroidal changes, it has been shown that the sclera is thinner with a loss of tissue, and the scleral thinning is accompanied by a narrowing and dissociation of the collagen fiber bundles and a reduction in the diameter of the collagen fibrils in mammalian myopia models ${ }^{14-16}$ and human myopic eyes. ${ }^{17,18}$

There have been several suggestions for the cause of the scleral thinning, for example, a downregulation of the production of certain extracellular matrix components, ${ }^{19,20}$ a downregulation of glycosaminoglycan ${ }^{16,21}$ and 
proteoglycan syntheses, ${ }^{22,23}$ a degradation of collagen enzymes such as MMP-2, ${ }^{24,25}$ FGF- $2,{ }^{26}$ and TGF- $\beta,{ }^{19,20,27}$ acting as retinoscleral signaling. However, the precise mechanisms causing the scleral changes have not been definitively determined.

With the advancement of optical coherence tomography (OCT), many studies on the morphology of the choroid have been published in the past 4 years. ${ }^{28-37}$ In our earlier study on the choroid of highly myopic eyes, we detected a thinner sclera by spectraldomain OCT because both the retina and choroid were very thin. ${ }^{38}$ This meant that we should be able to investigate the morphology of the sclera in highly myopic eyes.

Thus, the purpose of this study was to measure the scleral thickness at the fovea using enhanced depth imaging spectral-domain optical coherence tomography (EDI-OCT) in highly myopic eyes and to examine ocular parameters correlated with the thickness.

\section{Materials and methods}

We reviewed the medical records of patients with high myopia who were examined in the Department of Ophthalmology of the Nagoya University Hospital. These eyes were the fellow eyes or eyes that had myopic pathologies. The definition of high myopia was a refractive error $\geq-8.0$ diopters (D) or an axial length (AL) $\geq 26.5 \mathrm{~mm}$. Eyes with media opacities such as dense cataracts that prevented light from penetrating the media were excluded. None of the patients had undergone refractive surgery.

\section{Examinations}

The clinical examinations to diagnose pathologic myopia included measurement of the best-corrected visual acuity (BCVA), AL by partial coherence interferometry (IOL Master; Carl Zeiss Meditec, Dublin, CA, USA), refractive error (spherical equivalent) by an autorefractometer (Topcon, Tokyo, Japan), slit-lamp biomicroscopy with or without contact lens, and indirect ophthalmoscopy. The BCVA was measured with a Japanese standard decimal visual acuity chart, and the decimal VAs were converted to the logarithm of the minimum angle of resolution (logMAR) units for statistical analyses. Fundus color photographs and OCT images were taken of all eyes. Digital fluorescein angiography (FA) and indocyanine green angiography (ICGA; HRA2, version2.0; Heidelberg Engineering, Heidelberg, Germany) were performed in eyes with a subretinal hemorrhage or suspicious choroidal neovascularization (CNV).

\section{Data analyses}

We obtained six radial scans that were centered on the fovea within a $5 \times 30^{\circ}$ (73 eyes) or $5 \times 20^{\circ}$ ( 2 eyes) rectangle to encompass the macula with the Spectralis HRA + OCT (version 5.1, then later version 5.3; Heidelberg Engineering) using the enhanced depth imaging technique. To perform EDI-OCT, the OCT device was positioned close to the eye to obtain an inverted image, ${ }^{28}$ and a more recent EDI procedure that is built into the Heidelberg software was selected at the beginning of the scanning procedure. A total of 100 images were averaged to improve the signal-to-noise ratio.

A posterior staphyloma led to a tilting of the scleral OCT images in many eyes. Therefore, we selected the one scan out of the six radial scans that was most perpendicular to the sclera to measure the subfoveal scleral thickness. The scleral thickness was measured using the caliper tool in the OCT software, and the thickness was measured from the outer scleral border to the choroid/sclera interface in eyes whose outer scleral border could be clearly distinguished from the fat tissue in the retrobulbar orbit (Figure 1).

The height or depth of the posterior staphyloma was also measured in the superior, inferior, nasal, and temporal quadrants as reported. ${ }^{32,34}$ Briefly, the posterior staphyloma height was measured as the horizontal distance from the subfoveal retinal pigment epithelium (RPE) to the RPE $2 \mathrm{~mm}$ from the fovea in the four quadrants. The absolute and relative heights of the staphyloma were calculated and the relative height was recorded as a negative value and the absolute height was recorded as a positive value in eyes where the peripheral RPE was located posterior to the subfoveal RPE

(Figure 2).

The choroidal and retinal thicknesses at the fovea were also measured in the same image. However, the retinal thickness was measured only in eyes without retinochoroidal lesions, for example, $\mathrm{mCNV}$ or retinoschisis, which made the retina and choroid too thick to measure. The choroidal thickness was measured from the outer border of the hyperreflective line corresponding to the RPE to the inner sclera border. Eyes with a CNV were not measured.

The measurements obtained from the OCT images were performed by an experienced ophthalmologist $(\mathrm{MH})$ who was masked to the other parameters of the eye.

\section{Statement of ethics}

The protocol for this retrospective study was approved by the institutional review board of Nagoya University 


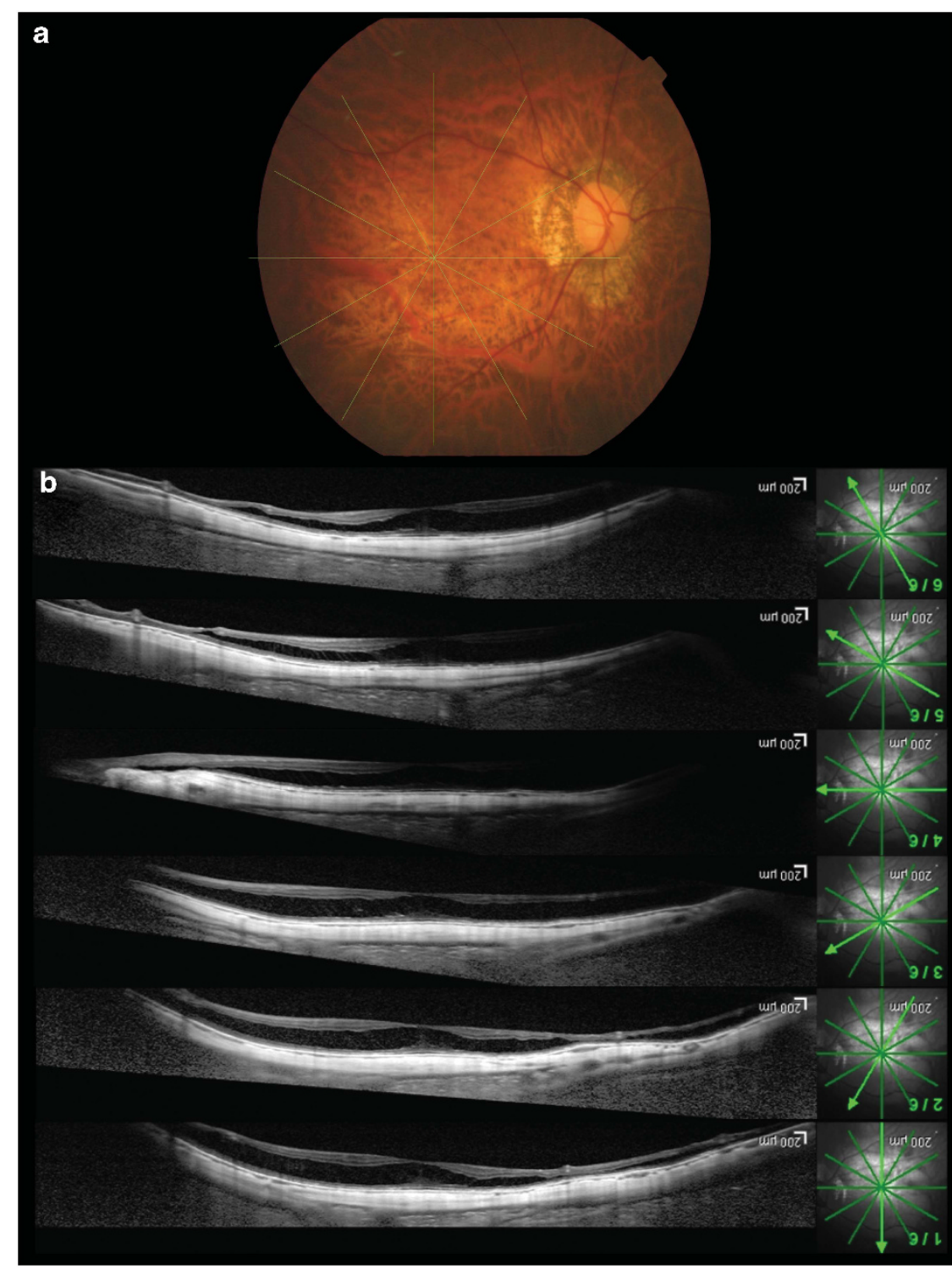

Figure 1 Fundus photographs and optical coherence tomographic findings in a highly myopic eye. (a) Fundus photograph of the right eye of a 57-year-old man. This eye was phakic and the refraction was -18.5 diopters. The axial length was $32.24 \mathrm{~mm}$. (b) Six radial enhanced depth imaging optical coherence tomography images. The outer scleral border can be clearly seen. Top of the images was most perpendicular to the sclera, and the subfoveal scleral thickness is $278 \mu \mathrm{m}$.

School of Medicine, and the procedures used conformed to the tenets of the Declaration of Helsinki.

\section{Reproducibility of scleral thickness measurements}

To evaluate the reproducibility of the technique, three of the authors (MH, AT, and KK) independently measured the scleral thickness of 30 eyes selected at random. In addition, one of the authors (MH) who obtained all measurements from the OCT images measured the scleral thickness of 30 eyes 3 times at more than 1-month intervals. The coefficients of variation were calculated.

\section{Statistical analyses}

Statistical analyses were performed with one-way analysis of variance (ANOVA), analysis of covariance (ANCOVA), single regression analysis, and stepwise regression analysis (PASW statistics version 18.0; SPSS Inc. and IBM Company, Chicago, IL, USA). The comparison of the subfoveal scleral thickness among the groups of eyes with and without retinochoroidal lesions was performed by ANCOVA after adjustments were made for the differences in the age of the patients. A $P<0.05$ was considered to be statistically significant. 


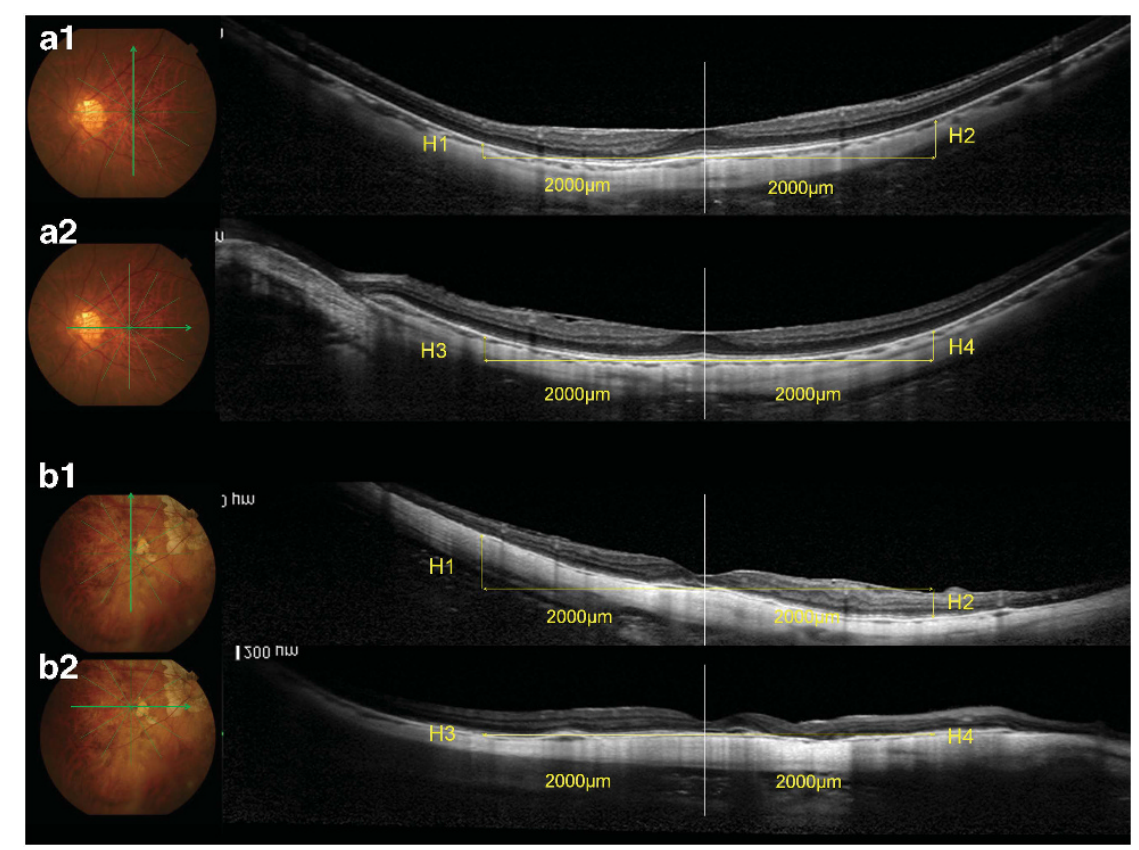

Figure 2 Morphologic parameters used in this study. A point $2 \mathrm{~mm}$ from the fovea on both sides was identified at which the posterior staphyloma height was measured. The height was defined as the horizontal distance between the subfoveal RPE line and that of either side. (a1 and a2) Fundus photographs and enhanced depth optical coherence tomography images of a 67-year-old man. All the relative values of the staphyloma heights as $\mathrm{H} 1-\mathrm{H} 4$ (the inferior, superior, nasal, and temporal quadrants) are positive values (H1, $91 \mu \mathrm{m}$; $\mathrm{H} 2$, $315 \mu \mathrm{m} ; \mathrm{H} 3,253 \mu \mathrm{m}$; and H4 $222 \mu \mathrm{m}$ ). A positive value means that the peripheral RPE $2 \mathrm{~mm}$ from the fovea is anterior to RPE at the fovea. (b1 and b2) Fundus photographs and enhanced depth optical coherence tomography images scanned along the green arrows of a 76-year-old woman. The relative value of the staphyloma height is a positive value as $\mathrm{H} 1, \mathrm{H} 4$ (the superior, nasal quadrant), and a negative value as $\mathrm{H} 2, \mathrm{H} 4$ (the inferior, nasal quadrant) $(\mathrm{H} 1,501 \mu \mathrm{m} ; \mathrm{H} 2,-26 \mu \mathrm{m} ; \mathrm{H} 3,-25 \mu \mathrm{m}$; and $\mathrm{H} 4,16 \mu \mathrm{m})$. A negative value means that the peripheral RPE $2 \mathrm{~mm}$ from the fovea is posterior to RPE at the fovea.

\section{Results}

In all, 75 eyes of 54 patients ( 21 men and 33 women) were examined by EDI-OCT. The average \pm SD age of the patients was $62.3 \pm 11.3$ years with a range of 29 to 83 years. The mean \pm SD AL was $30.24 \pm 1.68 \mathrm{~mm}$ with a range of 27.07 to $34.14 \mathrm{~mm}$. The mean spherical equivalent refractive error $\pm \mathrm{SD}$ was $-12.9 \pm 4.1 \mathrm{D}$ with a range of -6.3 to $-24.0 \mathrm{D}$ excluding the 25 eyes that were pseudophakic or aphakic (50 phakic eyes, 21 pseudophakic eyes, and 4 aphakic eyes). The mean decimal BCVA was $0.50 \pm 0.35(20 / 40)$ or $0.47 \pm 0.47$ $\log$ MAR units. The full thickness of the choroid and sclera was visible in all eyes.

The fundus was normal in 18 eyes of 17 patients and abnormal in 57 eyes of 52 patients; 17 eyes of 15 patients had myopic retinoschisis with and without retinal detachment, 25 eyes of 23 patients had myopic CNV with scars, 4 eyes of 4 patients had both myopic retinoschisis and scar of myopic CNV, and 11 eyes of 10 patients had other diseases such as retinal detachment, chorioretinal atrophy, epiretinal membrane, and macular hemorrhage without CNV. A dome-shaped macula was diagnosed in three eyes.

\section{Subfoveal scleral thickness in eyes with and without retinochoroidal lesions}

The mean \pm SD subfoveal scleral thickness for all 75 eyes was $284.1 \pm 70.4 \mu \mathrm{m}$ with a range of 132 to $434 \mu \mathrm{m}$. The mean scleral thickness was $293.6 \pm 59.6 \mu \mathrm{m}$ in the 18 eyes without myopic retinochoroidal lesions, $277.5 \pm 69.5 \mu \mathrm{m}$ in 17 eyes with myopic retinoschisis with and without retinal detachment, $307.2 \pm 70.0 \mu \mathrm{m}$ in 25 eyes with scarring of a myopic $\mathrm{CNV}$, and $241.3 \pm 70.1 \mu \mathrm{m}$ in the other 15 eyes. None of these differences were significant. There were no significant differences in the age and AL between the eyes with the different kinds of myopic retinochoroidal lesions $(P>0.05$; Table 1$)$. In addition, we performed analyses in view of potential age difference. However, there were no significant differences in the scleral thickness between the eyes with the different kinds of myopic retinochoroidal lesions $(P=0.40)$.

The thickness of the retina at the fovea of eyes without myopic retinochroidal lesions was $226.9 \pm 42.6 \mu \mathrm{m}$ with a range 175 to $337 \mu \mathrm{m}$, and that of the choroid in eyes without a myopic CNV scar was $41.7 \pm 20.6 \mu \mathrm{m}$ with a range of 11 to $105 \mu \mathrm{m}$. 
Table 1 The scleral thickness and clinical characteristics of the eyes in each group with and without retinochoroidal lesion

\begin{tabular}{lcccc}
\hline & $\begin{array}{c}\text { Eyes without } \\
\text { retinochoroidal } \\
\text { lesion }\end{array}$ & $\begin{array}{c}\text { Myopic } \\
\text { retinoschisis }\end{array}$ & $m$ CNV & P-value \\
\hline No. of eyes & 18 & 17 & 25 & \\
$\begin{array}{l}\text { Age (years) } \\
\begin{array}{l}\text { Axial length } \\
(\mathrm{mm})\end{array}\end{array}$ & $61.1 \pm 11.1$ & $62.6 \pm 13.1$ & $63.2 \pm 10.7$ & 0.83 \\
$\begin{array}{l}\text { Scleral } \\
\text { thickness }(\mu \mathrm{m})\end{array}$ & $293.6 \pm 59.6$ & $30.7 \pm 1.2$ & $29.9 \pm 1.4$ & 0.16 \\
\hline
\end{tabular}

Abbreviations: Myopic retinoschisis, myopic retinoschisis with and without retinal detachment and macular hole retinal detachment; $\mathrm{mCNV}$, myopic choroidal neovascularization.

Data are the mean \pm SD.

\section{Correlation of ocular parameters and subfoveal scleral thickness}

Simple regression analysis showed that the thickness of the sclera at the fovea was significantly negatively correlated with the absolute value of the nasal and overall average posterior staphyloma height $(P<0.05$ and $P<0.01$, respectively; Table 2 ), and the relative value of the superior, nasal, and overall average posterior staphyloma height $(P<0.05$ and $P<0.01, P<0.001$, respectively; Table 2 and Figure 3 ). The thickness of the sclera was not significantly associated with age, BCVA, refractive error, AL, subfoveal retinal thickness, subfoveal choroidal thickness, the absolute value of the superior, inferior, temporal staphyloma heights, and the relative value of the inferior and temporal staphyloma heights $(P>0.05$; Table 2$)$. Age was also significantly associated with the choroidal thickness $(P<0.01)$.

Stepwise analysis showed that the factor most associated with the scleral thickness was the average relative posterior staphyloma height $(\mathrm{F}=16.0, P<0.001)$.

\section{Reproducibility of scleral thickness measurements}

The coefficient of variance for the reproducibility of the measurements of subfoveal scleral thickness using EDIOCT was relatively good. The coefficient of variance by three coauthors ranged from 1.0 to $17.1 \%$ with a mean of $5.3 \pm 3.7 \%$ (mean $\pm \mathrm{SD}$ ), and the coefficient of variance by one of the authors $(\mathrm{MH})$ ranged from 0.04 to $15.7 \%$ with a mean of $3.7 \pm 3.1 \%$ for the three measurements.

\section{Discussion}

We were able to obtain clear images of the sclera by EDI-OCT and measure the scleral thickness at the fovea. Our in situ measurements showed that the mean of the subfoveal scleral thickness of highly myopic eyes was 284.1 with a range of 132 to $434 \mu \mathrm{m}$.

Curtin et al ${ }^{17}$ reported that the scleral thickness of postmortem eyes without axial elongation was $0.66 \mathrm{~mm}$ in the posterior pole. They also measured the scleral thickness at the posterior pole of 10 postmortem myopic eyes, and the mean of the scleral thickness was $233 \mu \mathrm{m} .{ }^{17}$ Olsen et $\mathrm{al}^{39}$ reported that the scleral thickness near the optic nerve of eyes fixed in formalin was 0.9 to $1.0 \mathrm{~mm}$, and Norman et al ${ }^{40}$ reported that the average scleral thickness at the posterior pole of eyes after fixation using high-field microMRI was $996 \mu \mathrm{m}$. The eyes of both studies were not only highly myopic eyes but also eyes without axial elongation. In addition, there was a certain degree of distortion and shrinkage as a result of fixation.

Imamura et $a l^{41}$ reported that the mean subfoveal scleral thickness measured by EDI-OCT in 25 eyes with high myopia without dome-shaped macula was $281 \mu \mathrm{m}$. Maruko et al $^{42}$ reported that the mean subfoveal scleral thicknesses in 58 highly myopic eyes measured by highpenetration (HP) OCT was $335 \mu \mathrm{m}$.

Despite differences in the methods of measuring the thickness, a thinner sclera was found in highly myopic eyes than eyes without axial elongation. Several studies have reported a decrease in the amount of scleral tissue and a reduction of collagen fibril diameter in highly myopic eyes. ${ }^{14-18,21}$ These changes may account for the thinner sclera we have found.

Our results showed that the subfoveal scleral thickness was significantly associated with the posterior staphyloma height. Maruko et al ${ }^{42}$ reported that the subfoveal scleral thickness in eyes with a posterior staphyloma was significantly thinner than that without posterior staphyloma in highly myopic eyes, and they reported that the sclera at the posterior pole in highly myopic eyes stretches nonuniformly.

Among the four quadrants, the nasal and superior posterior staphyloma heights were significantly associated with subfoveal scleral thickness. Our earlier report showed that the progression of axial elongation was most significantly associated with superior RPE curvature. ${ }^{38}$ Ikuno et al ${ }^{34}$ reported that the nasal posterior staphyloma height was significantly greater in eyes with a mCNV than in eyes without a mCNV.

The mechanical stretching nasally and superiorly around the fovea influences the subfoveal scleral thinning, and the staphyloma in this area may be associated with axial elongation and the presence of myopic fundus lesions.

Our stepwise regression analyses showed that the relative average staphyloma height was most significantly associated with the scleral thinning. The relative staphyloma height is the horizontal distance in the anterior direction between the subfoveal RPE and the 
Table 2 Correlation of ocular parameters and subfoveal scleral thickness

\begin{tabular}{|c|c|c|c|c|}
\hline & $M e a n \pm S D$ & Coefficient & $\mathrm{R}^{2}$ & P-value \\
\hline Age (years) & $62.3 \pm 11.3$ & & & 0.29 \\
\hline $\log$ MAR visual acuity & $0.47 \pm 0.47$ & & & 0.65 \\
\hline Axial length (mm) & $30.24 \pm 1.68$ & & & 0.45 \\
\hline Refractive error (D) & $-12.9 \pm 4.1$ & & & 0.63 \\
\hline Subfoveal retinal thickness $(\mu \mathrm{m})$ & $226.9 \pm 42.6$ & & & 0.96 \\
\hline Subfoveal choroidal thickness $(\mu \mathrm{m})$ & $41.7 \pm 20.6$ & & & 0.77 \\
\hline \multicolumn{5}{|l|}{ Posterior staphyloma height } \\
\hline \multicolumn{5}{|l|}{ Relative measurements } \\
\hline Average of 4 measurements $(\mu \mathrm{m})$ & $152.7 \pm 93.7$ & -0.32 & 0.18 & $<0.001$ \\
\hline Nasal region $(\mu \mathrm{m})$ & $173.7 \pm 127.7$ & -0.21 & 0.14 & $<0.01$ \\
\hline Temporal region $(\mu \mathrm{m})$ & $170.1 \pm 136.2$ & & & 0.09 \\
\hline Superior region $(\mu \mathrm{m})$ & $183.0 \pm 214.7$ & -0.097 & 0.087 & $<0.05$ \\
\hline Inferior region $(\mu \mathrm{m})$ & $83.9 \pm 201.6$ & & & 0.35 \\
\hline \multicolumn{5}{|l|}{ Absolute measurements } \\
\hline Average of 4 measurements $(\mu \mathrm{m})$ & $192.7 \pm 78.6$ & -0.26 & 0.083 & $<0.05$ \\
\hline Nasal region $(\mu \mathrm{m})$ & $185.9 \pm 109.0$ & -0.22 & 0.011 & $<0.01$ \\
\hline Temporal region $(\mu \mathrm{m})$ & $180.4 \pm 122.0$ & & & 0.23 \\
\hline Superior region $(\mu \mathrm{m})$ & $232.4 \pm 159.0$ & & & 0.099 \\
\hline Inferior region $(\mu \mathrm{m})$ & $172.0 \pm 133.4$ & & & 0.74 \\
\hline
\end{tabular}

Abbreviations: $\log$ MAR, logarithm of minimum angle of resolution.

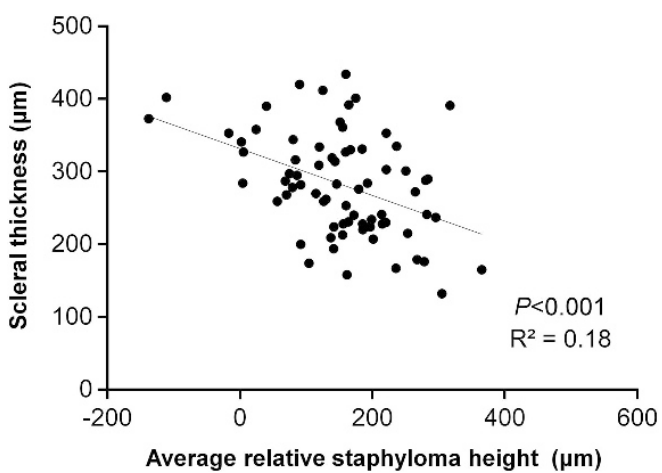

Figure 3 Scattergram showing the relationship between the average relative posterior staphyloma height and the subfoveal scleral thickness. The coefficient of correlation is $r=0.43$; $P<0.001$.

peripheral RPE. This indicates that the more forward the tissue around fovea curves, the thinner will be the sclera at the fovea. Thus, the shape of the staphyloma around the fovea may influence the scleral thickness at the fovea.

Our results showed that the scleral thickness was not significantly different whether the fundus had myopic retinochoroidal pathologies or not. Earlier studies reported that there was a mechanical stretching of the eyes with a staphyloma that resulted in a thinner choroid and changes of the choroidal vascular structures. ${ }^{32,43,44}$ Steidl and Pruett ${ }^{45}$ reported that chorioretinal atrophy, conus formation, and laquer cracks were significantly associated with increasing staphyloma depth, and shallower staphylomas tended to cause CNVs.
Ikuno $e a^{34}$ showed that the posterior staphyloma height was significantly greater in eyes without than with a myopic neovascularization. A mechanical stretching by an extension of a staphyloma may have a more direct effect on the myopic complications than scleral thinning.

There are several limitations in this study. The staphyloma height was measured at $2 \mathrm{~mm}$ from the fovea, but the staphyloma can have different shapes, such as nasal, macula-centered, disc-centered, and compound staphylomas. ${ }^{46}$ In a recent study with highresolution 3D MRI, eyes with pathologic myopia were found to have multiple posterior protrusions, that is, posterior staphylomas, located at different positions on the posterior surface of the eye. ${ }^{47}$ We only measured the subfoveal scleral thickness and staphyloma height $2 \mathrm{~mm}$ from the fovea. In the future, with the advancement of OCT, we should be capable of examining a broader area surrounding the macula and the optic disc. These findings should then allow us to determine that a significant correlation exists between the sclera and staphyloma formation.

Another limitation is that the patients were not randomly sampled. There is a possibility that we have chosen more extremely myopic patients whose sclera was thinner among all highly myopic eyes because patients with ocular symptoms were studied. However, we can examine relatively more patients noninvasively and follow the same individual longitudinally, and this is ongoing in our laboratory.

In conclusion, we measured the scleral thickness at the fovea in highly myopic eyes using EDI-OCT. The 
subfoveal scleral thickness in highly myopic eyes was significantly associated with posterior staphyloma height. The average relative staphyloma height was most significantly associated with the scleral thickness. The posterior staphyloma formation and the subfoveal scleral thinning were closely related in highly myopic eyes.

\section{Summary}

What was known before

- The sclera of highly myopic eyes is thinner with a loss of scleral tissue. The scleral thinning is accompanied by a narrowing and dissociation of the collagen fiber bundles and a reduction in the diameter of the collagen fibrils. However, there are few in situ studies on scleral thickness.

\section{What this study adds}

- The results of this study showed that the ocular parameter that was significantly associated with the scleral thickness in highly myopic eyes, measured by spectral domain optical coherence tomography, was the posterior staphyloma height. The scleral thickness was not significantly associated with the presence of myopic retinochoroidal lesions. Posterior staphyloma formation and subfoveal scleral thinning were closely related in highly myopic eyes.

\section{Conflict of interest}

The authors declare no conflict of interest.

\section{Acknowledgements}

We thank Professor Duco Hamasaki of the Bascom Palmer Eye Institute for his critical discussion and final manuscript revision. The grant support was the grant-in aid for Scientific Research from the Ministry of Education, Culture, Sports, Science, and Technology of Japan (C2159225; to Y Ito).

\section{References}

1 Sperduto RD, Seigel D, Roberts J, Rowland M. Prevalence of myopia in the United States. Arch Ophthalmol 1983; 101: 405-407.

2 Fledelius HC. Myopia prevalence in Scandinavia. A survey, with emphasis on factors of relevance for epidemiological refraction studies in general. Acta Ophthalmol Suppl 1988; 185: 44-50.

3 Wang Q, Klein BE, Klein R, Moss SE. Refractive status in the Beaver Dam Eye Study. Invest Ophthalmol Vis Sci 1994; 35: 4344-4347.

4 Attebo K, Ivers RQ, Mitchell P. Refractive errors in an older population: the Blue Mountains Eye Study. Ophthalmology 1999; 106: 1066-1072.

5 Saw SM, Katz J, Schein OD, Chew SJ, Chan TK. Epidemiology of myopia. Epidemiol Rev 1996; 18: 175-187.
6 Wensor M, McCarty CA, Taylor HR. Prevalence and risk factors of myopia in Victoria, Australia. Arch Ophthalmol 1999; 117: 658-663.

7 Midelfart A, Midelfart S. Prevalence of refractive errors among adults in Europe. Arch Ophthalmol 2005; 123: 580.

8 Tokoro T. On the definition of pathologic myopia in group studies. Acta Ophthalmol Suppl 1988; 185: 107-108.

9 Wong TY, Foster PJ, Hee J, Ng TP, Tielsch JM, Chew SJ et al. Prevalence and risk factors for refractive errors in adult Chinese in Singapore. Invest Ophthalmol Vis Sci 2000; 41: 2486-2494.

10 Rosenberg T, Klie F. Current trends in newly registered blindness in Denmark. Acta Ophthalmol Scand 1996; 74: 395-398.

11 Iwase A, Araie M, Tomidokoro A, Yamamoto T, Shimizu H, Kitazawa Y. Prevalence and causes of low vision and blindness in a Japanese adult population: the Tajimi Study. Ophthalmology 2006; 113: 1354-1362.

12 Xu L, Wang Y, Li Y, Cui T, Li J, Jonas JB. Causes of blindness and visual impairment in urban and rural areas in Beijing: the Beijing Eye Study. Ophthalmology 2006; 113(1134): e1131-1111.

13 Cotter SA, Varma R, Ying-Lai M, Azen SP, Klein R. Causes of low vision and blindness in adult Latinos: the Los Angeles Latino Eye Study. Ophthalmology 2006; 113: 1574-1582.

14 McBrien NA, Cornell LM, Gentle A. Structural and ultrastructural changes to the sclera in a mammalian model of high myopia. Invest Ophthalmol Vis Sci 2001; 42: 2179-2187.

15 McBrien NA, Gentle A. Role of the sclera in the development and pathological complications of myopia. Prog Retin Eye Res 2003; 22: 307-338.

16 McBrien NA, Gentle A, Cottriall C. Optical correction of induced axial myopia in the tree shrew: implications for emmetropization. Optom Vis Sci 1999; 76: 419-427.

17 Curtin BJ, Teng CC. Scleral changes in pathological myopia. Trans Am Acad Ophthalmol Otolaryngol 1958; 62: 777-788; discussion 788-790.

18 Curtin BJ, Iwamoto T, Renaldo DP. Normal and staphylomatous sclera of high myopia. An electron microscopic study. Arch Ophthalmol 1979; 97: 912-915.

19 Seko Y, Shimokawa H, Tokoro T. Expression of bFGF and TGF-beta 2 in experimental myopia in chicks. Invest Ophthalmol Vis Sci 1995; 36: 1183-1187.

20 Rohrer B, Stell WK. Basic fibroblast growth factor (bFGF) and transforming growth factor beta (TGF-beta) act as stop and go signals to modulate postnatal ocular growth in the chick. Exp Eye Res 1994; 58: 553-561.

21 McBrien NA, Lawlor P, Gentle A. Scleral remodeling during the development of and recovery from axial myopia in the tree shrew. Invest Ophthalmol Vis Sci 2000; 41: 3713-3719.

22 Rada JA, Nickla DL, Troilo D. Decreased proteoglycan synthesis associated with form deprivation myopia in mature primate eyes. Invest Ophthalmol Vis Sci 2000; 41: 2050-2058.

23 Rada JA, Shelton S, Norton TT. The sclera and myopia. Exp Eye Res 2006; 82: 185-200.

24 Guggenheim JA, McBrien NA. Form-deprivation myopia induces activation of scleral matrix metalloproteinase-2 in tree shrew. Invest Ophthalmol Vis Sci 1996; 37: 1380-1395.

25 Rada JA, Brenza HL. Increased latent gelatinase activity in the sclera of visually deprived chicks. Invest Ophthalmol Vis Sci 1995; 36: 1555-1565. 
26 Gentle A, McBrien NA. Retinoscleral control of scleral remodelling in refractive development: a role for endogenous FGF-2? Cytokine 2002; 18: 344-348

27 McBrien NA, Jobling AI, Gentle A. Biomechanics of the sclera in myopia: extracellular and cellular factors. Optom Vis Sci 2009; 86: E23-E30.

28 Spaide RF, Koizumi H, Pozzoni MC. Enhanced depth imaging spectral-domain optical coherence tomography. Am J Ophthalmol 2008; 146: 496-500.

29 Margolis R, Spaide RF. A pilot study of enhanced depth imaging optical coherence tomography of the choroid in normal eyes. Am J Ophthalmol 2009; 147: 811-815.

30 Imamura Y, Fujiwara T, Margolis R, Spaide RF. Enhanced depth imaging optical coherence tomography of the choroid in central serous chorioretinopathy. Retina 2009; 29: 1469-1473.

31 Spaide RF. Enhanced depth imaging optical coherence tomography of retinal pigment epithelial detachment in age-related macular degeneration. Am J Ophthalmol 2009; 147: 644-652.

32 Ikuno Y, Tano Y. Retinal and choroidal biometry in highly myopic eyes with spectral-domain optical coherence tomography. Invest Ophthalmol Vis Sci 2009; 50: 3876-3880.

33 Fujiwara T, Imamura Y, Margolis R, Slakter JS, Spaide RF. Enhanced depth imaging optical coherence tomography of the choroid in highly myopic eyes. Am J Ophthalmol 2009; 148: 445-450.

34 Ikuno Y, Jo Y, Hamasaki T, Tano Y. Ocular risk factors for choroidal neovascularization in pathologic myopia. Invest Ophthalmol Vis Sci 2010; 51: 3721-3725.

35 Ikuno Y, Kawaguchi K, Nouchi T, Yasuno Y. Choroidal thickness in healthy Japanese subjects. Invest Ophthalmol Vis Sci 2010; 51: 2173-2176.

36 Maruko I, Iida T, Sugano Y, Ojima A, Sekiryu T. Subfoveal choroidal thickness in fellow eyes of patients with central serous chorioretinopathy. Retina 2011; 31: 1603-1608.

37 Maruko I, Iida T, Sugano Y, Ojima A, Ogasawara M, Spaide RF. Subfoveal choroidal thickness after treatment of central serous chorioretinopathy. Ophthalmology 2010; 117: 1792-1799.

38 Takahashi A, Ito Y, Iguchi Y, Yasuma TR, Ishikawa K, Terasaki H. Axial length increases and related changes in highly myopic normal eyes with myopic complications in fellow eyes. Retina 2012; 32: 127-133.

39 Olsen TW, Aaberg SY, Geroski DH, Edelhauser HF. Human sclera: thickness and surface area. Am J Ophthalmol 1998; 125: 237-241.

40 Norman RE, Flanagan JG, Rausch SM, Sigal IA, Tertinegg I, Portnoy $S$ et al. Dimensions of the human sclera: thickness measurement and regional changes with axial length. Exp Eye Res 2010; 90: 277-284.

41 Imamura Y, Iida T, Maruko I, Zweifel SA, Spaide RF. Enhanced depth imaging optical coherence tomography of the sclera in dome-shaped macula. Am J Ophthalmol 2011; 151: 297-302.

42 Maruko I, Iida T, Sugano Y, Oyamada H, Akiba M, Sekiryu T. Morphologic analysis in pathologic myopia using highpenetration optical coherence tomography. Invest Ophthalmol Vis Sci 2012; 53: 3834-3838.

43 Wakabayashi T, Ikuno Y. Choroidal filling delay in choroidal neovascularisation due to pathological myopia. $\mathrm{Br} \mathrm{J}$ Ophthalmol 2010; 94: 611-615.

44 Ohno-Matsui K, Morishima N, Ito M, Yamashita S, Futagami S, Tokoro T et al. Indocyanine green angiography of retrobulbar vascular structures in severe myopia. Am J Ophthalmol 1997; 123: 494-505.

45 Steidl SM, Pruett RC. Macular complications associated with posterior staphyloma. Am J Ophthalmol 1997; 123: 181-187.

46 Curtin BJ. The posterior staphyloma of pathologic myopia. Trans Am Ophthalmol Soc 1977; 75: 67-86.

47 Moriyama M, Ohno-Matsui K, Hayashi K, Shimada N Yoshida T, Tokoro T et al. Topographic analyses of shape of eyes with pathologic myopia by high-resolution threedimensional magnetic resonance imaging. Ophthalmology 2010; 118: 1626-1637. 